\title{
The Role of Ethnography in the Design and Implementation of IT Systems
}

\author{
Simonsen, Jesper
}

Published in:

Design Principles and Practices: An International Journal

\section{Publication date:}

2009

Document Version

Peer reviewed version

Citation for published version (APA):

Simonsen, J. (2009). The Role of Ethnography in the Design and Implementation of IT Systems. Design

Principles and Practices: An International Journal, 3(3), 251. http://ijg.cgpublisher.com/product/pub.154/prod.206

\section{General rights}

Copyright and moral rights for the publications made accessible in the public portal are retained by the authors and/or other copyright owners and it is a condition of accessing publications that users recognise and abide by the legal requirements associated with these rights.

- Users may download and print one copy of any publication from the public portal for the purpose of private study or research.

- You may not further distribute the material or use it for any profit-making activity or commercial gain.

- You may freely distribute the URL identifying the publication in the public portal.

Take down policy

If you believe that this document breaches copyright please contact rucforsk@kb.dk providing details, and we will remove access to the work immediately and investigate your claim. 


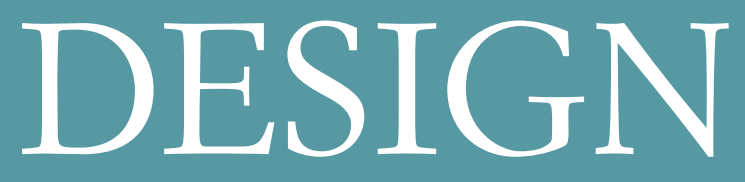

Principles \& Practices:

An International Journal

Volume 3

The Role of Ethnography in the Design and Implementation of IT Systems

Jesper Simonsen 
DESIGN PRINCIPLES AND PRACTICES: AN INTERNATIONAL JOURNAL http://www.Design-Journal.com

First published in 2009 in Melbourne, Australia by Common Ground Publishing Pty Ltd www.CommonGroundPublishing.com.

(C) 2009 (individual papers), the author(s)

(C) 2009 (selection and editorial matter) Common Ground

Authors are responsible for the accuracy of citations, quotations, diagrams, tables and maps.

All rights reserved. Apart from fair use for the purposes of study, research, criticism or review as permitted under the Copyright Act (Australia), no part of this work may be reproduced without written permission from the publisher. For permissions and other inquiries, please contact

<cg-support@commongroundpublishing.com>.

ISSN: 1833-1874

Publisher Site: http://www.Design-Journal.com

DESIGN PRINCIPLES AND PRACTICES: AN INTERNATIONAL JOURNAL is peerreviewed, supported by rigorous processes of criterion-referenced article ranking and qualitative commentary, ensuring that only intellectual work of the greatest substance and highest significance is published.

Typeset in Common Ground Markup Language using CGCreator multichannel typesetting system

http://www.commongroundpublishing.com/software/ 


\title{
The Role of Ethnography in the Design and Implementation of IT Systems
}

\author{
Jesper Simonsen, Roskilde University, Denmark
}

\begin{abstract}
Ethnographic workplace studies in design tend to focus on the existing work practices either to inform the initial design of new information technology (IT) systems or as studies evaluating work practices after a system has been implemented and taken into use. However, ethnography may also prove efficient in identifying, analyzing, and evaluating changes in work practices that emerge from using the IT system as part of the design and implementation of this system. This is possible since the technical frameworks used for large IT systems are becoming highly configurable. This article presents an example from a case where a fully functional prototype of a large Electronic Patient Record (EPR) system was designed, implemented, used as a pilot study, and subjected to evaluations based on ethnographic observations. The case demonstrates how a new and important role for ethnography can be established as an integral part of iterative approaches to design and organizational implementation of large IT systems. The role of ethnography can be expanded from a descriptive role (describing existing work practices or the situation after a complete implementation) to a constructive role focusing on appropriating new IT to the work practices of the users.
\end{abstract}

Keywords: Ethnography, Workplace Studies, Design and Implementation, Large IT Systems, Participatory Design, Iterative Approaches, Electronic Patient Record (EPR), Large, Shared EPR Display, Pilot Study, Experiment, Evaluation, Emergent Changes, Empowerment, Nurses

\section{Introduction}

$\mathrm{I}$

N A DESIGN context the aim of ethnography is to develop a thorough understanding of work practices as a basis for the design of IT systems (Simonsen and Kensing, 1997; 1998). A major tenet of ethnography is that work is a socially organized activity where the actual behavior differs from how it is described, prescribed, or envisioned. This implies that ethnographically inspired workplace studies must include observations, and when possible observations supported by video analyses (Blomberg et al., 1993).

Ethnographic workplace studies are an established approach both within design as well as within evaluations of the use of IT systems that support work organization and work practices in organizations. For large IT systems, ethnography has traditionally been used in two different ways: (1) analyzing the existing work practices (prior to system implementation), in order to inform a subsequent design and implementation of new IT systems, or (2) as studies evaluating work practices after a system have been fully implemented and taken into use. (See figure 1).

Using ethnography in design (left side of figure 1) has been acknowledged especially within the fields of Participatory Design (PD) (e.g. Greenbaum and Kyng, 1991; Schuler and Namioka, 1993; Bødker et al., 2004) and Computer Supported Cooperative Work (CSCW) (e.g. Sommerville et al., 1992; Hughes et al., 1993; Luff et al., 2000).

Design Principles and Practices: An International Journal Volume 3, 2009, http://www.Design-Journal.com, ISSN 1833-1874 


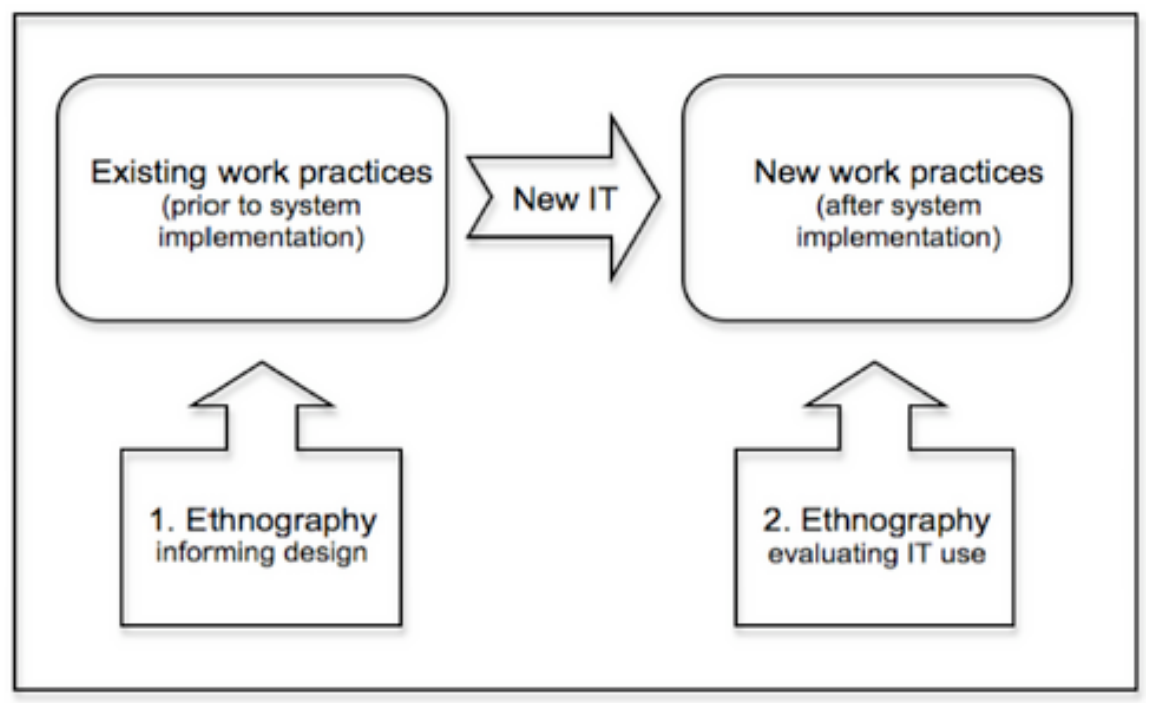

Figure 1: Two Traditional Roles for Ethnography with Regards to Large IT Systems

The projects reported on in the PD literature have been restricted to small-scale systems often driven by researchers (Oostveen, Clement and Besselaar, 1993; Oostveen and Besselaar, 2004) or to the initial phase of larger-scale information-systems development followed by a conventional contractual bid (Kensing, 2000; Bødker et al., 2004). An example is the renowned UTOPIA project (Ehn, 1988), concerning a large-scale information system that only included an initial design phase. Large-scale PD projects using ethnography have also been undertaken in the Danish Radio (Kensing et al., 1998) and Maersk shipping (Christensen et al., 1998) companies. These projects included initial design but were followed up by a contractual bid and a conventional procurement and implementation process. The CSCW literature reveals a similar pattern as PD. Plowman et al.'s (1995) extensive literature review describe a dominant approach of sociologists conducting the ethnographic studies of existing work practices before the introduction of new IT and informing designers of their findings, such as in debriefing meetings (for examples see Sommerville et al., 1992; Hughes et al., 1993; Luff et al., 2000).

Evaluations of the use of IT (right side of figure 1) is generally known from Science and Technology Studies (STS) (Sismondo, 2003) and in particular with regard to large IT systems within sociotechnical studies related to the healthcare domain (Berg, 1999; Berg et al., 2003; Stoop and Berg, 2003). Ethnographically based evaluations of IT systems in use resemble the above mentioned workplace studies from PD and CSCW. Pirnejad et al. (2008) evaluated the impact of a physician order entry IT system with an analysis including both the situation before the system was implemented as well as after it was brought into use. Evaluation studies provide important insights and implications in general with regard to the design of new large IT systems. Although they might be not related to the design process within a specific IT project. For example, Jirotka et al. (2005) highlighted the importance of trust, accountability, and visibility of work in a case where clinicians used a system supporting distributed use of breast cancer screening. Hartswood et al. (2003b) conducted an ethnographic analysis of work at a toxicology ward. This analysis stressed the clinicians' efforts in interpreting the available information, achieving mutual understanding and alignment, and 
reaching an agreement on how to proceed with patient treatment. Hartswood et al. (2003a, p. 392) argued for the need of analyses focusing on "what happens as the [clinician] grapple with the problems of applying IT, appropriating its functionalities and affordances into their work practices and relations". In this article we demonstrate how this can be done as an integrated part of iterative approaches to design and organizational implementation of large IT systems.

The iterative prototyping approach is well-known within information systems (IS) in general (Floyd, 1984; Budde et al., 1992). Prototyping refers to the process of creating a working model in advance (a prototype), that exhibits essential features of the final product (the IT system) and in order to test various aspects of a design, illustrate ideas or features, and finally gather early feedback and experiences from usage. The iterative approach is most often illustrated as an iterative process reflecting the hermeneutic circle as in the task-artifact cycle presented by Carroll et al. (1991) (see figure 2). The task-artifact cycle outlines an evolution when introducing new IT systems because the implementation of IT impacts the task and hereby opens up for new possibilities: "A task implicitly sets the requirements for the development of artifacts to support it; an artifact suggests possibilities and introduces constraints that often radically redefine the task for which the artifact was originally developed" (ibid, p.79). Carroll et al., (1991) suggest the use of scenarios in order to help the users to better imagine the implications of the envisioned IT systems.

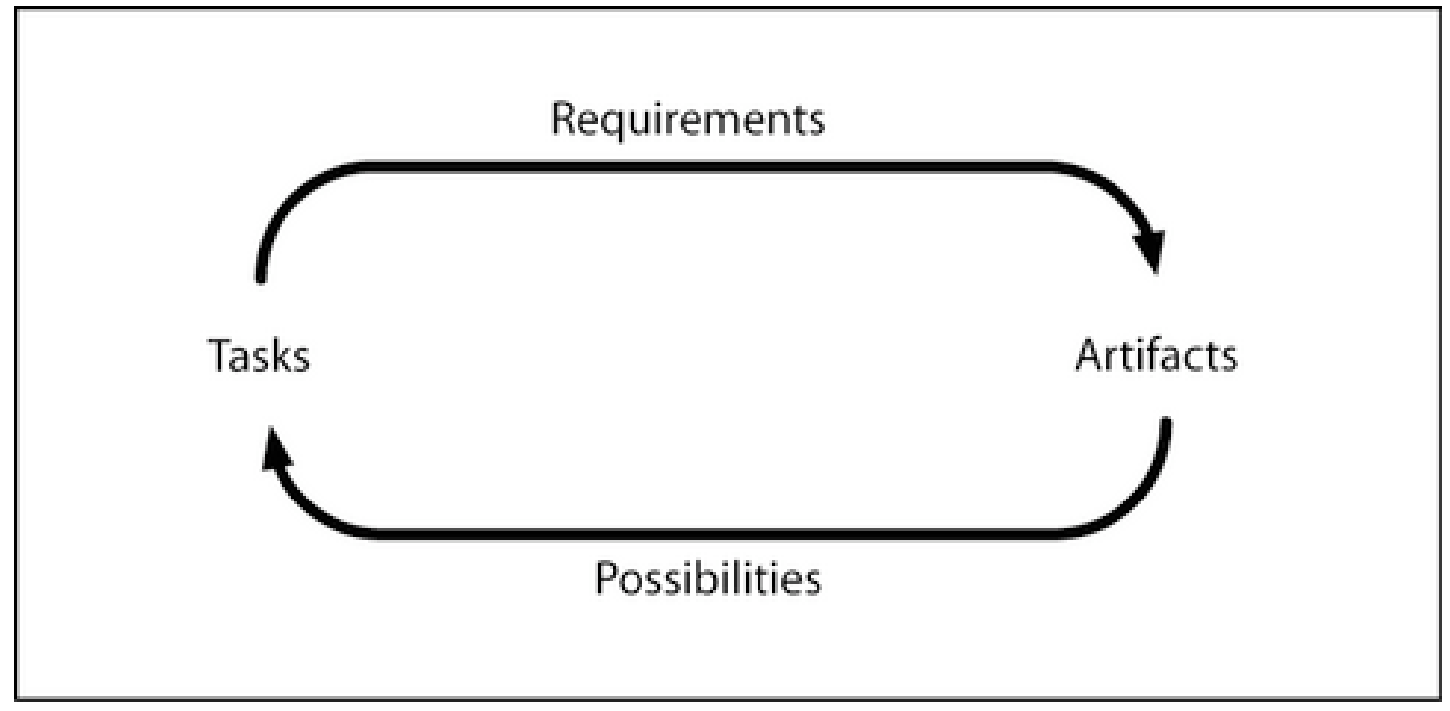

Figure 2: The Task-Artifact Cycle Presented by Carroll et al (1991)

Studies of small groupware systems that allow quick 'evolutions' (in terms of design, use, and subsequent redesign of the application) have stressed the point of actually using the IT system supporting real situated work tasks in order to comprehend the possibilities and constraints imposed by the artifact. Orlikowski and Hofman (1997) have characterized this as 'improvisational change management' and made the distinction between anticipated and unanticipated change - where the latter might be further distinguished as emergent and opportunity-based change. Anticipated change is planned ahead and occurs as intended by the originators of the change. Emergent change is defined as local and spontaneous change, not originally anticipated nor intended. Such change does not involve deliberate actions but grows out of practice. Opportunity-based change is purposefully introduced change resulting 
from unexpected opportunities, events, or breakdowns that possibly arise after the introduction of a new information system: "Over time, however, use of the new technology will typically involve a series of opportunity-based, emergent, and further anticipated changes, the order of which cannot be determined in advance because the changes interact with each other in response to outcomes, events, and conditions arising through experimentation and use" (ibid, p.13). Though this is very much in line with the findings from the ethnographic evaluation studies mentioned above, the question is, if such an 'improvisational' iterative approach is possible with regards to large IT systems.

Traditionally, iterative prototyping has been conducted as the initial phase of an overall development process using exploratory and experimental prototypes and leading to a contractual bid (in commercial settings) (Kensing, 2000; Bødker et al., 2004). And typically, the development process succeeding the contractual bid is based on a traditional sequential waterfall type process, where the system is 'rolled out' in the organization (Davis, 1990).

Today however, large-scale IT systems are increasingly changed from being standard, one-size-fits-all systems to an 'era of configurability' (Balka et al., 2005) including flexible, generic frameworks (Bansler and Havn, 1994). Configurable frameworks include high-level configuration tools (typically XML based) and embed standard interfaces for other systems as well as general business logic for specific domains. One example is the Oracle Healthcare Transaction Base (HTB) ${ }^{\mathrm{TM}}$, which forms a development framework that enables an agile modeling of processes and objects native to the healthcare domain. Such generic frameworks can be relatively efficiently configured to support individual needs in a manner comparable to earlier studies of small groupware applications (e.g. Orlikowski, 1996; Bentley et al., 1997; Appelt, 1999).

The 'era of configurability' introduces increasingly mature technological means for an iterative, real-life experimentation-based design approach, comprising design as well as organizational implementation of large IT systems. Evaluations within the iterative cycles enable a new role of ethnography by identifying and analyzing changes to work practices that emerge from experimental use of the IT system (see figure 3).

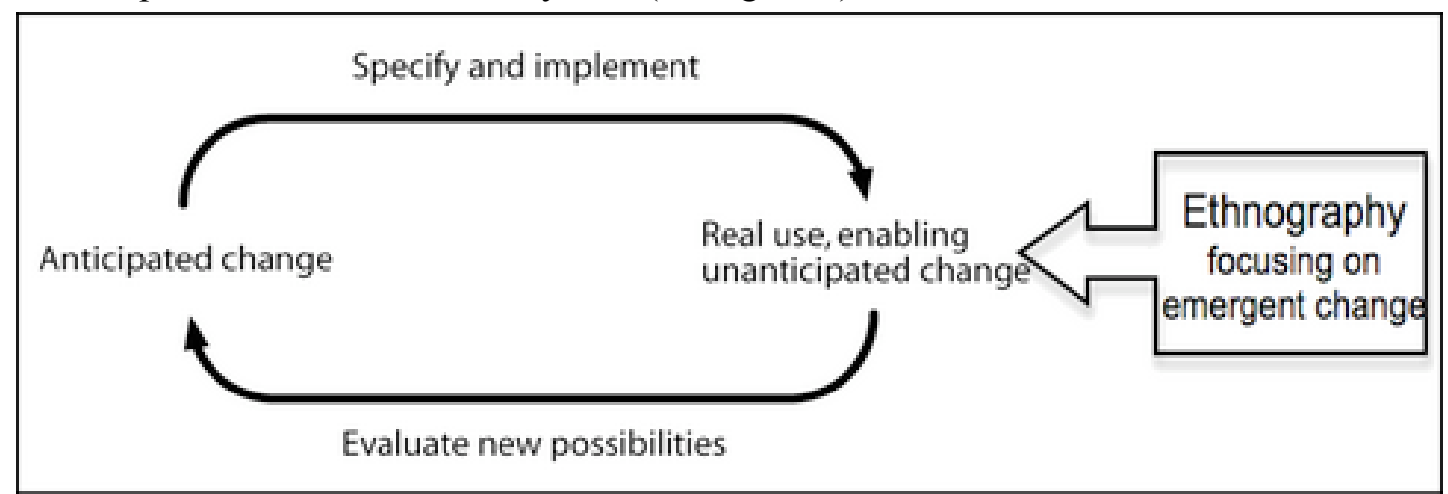

Figure 3: A New Role for Ethnography as an Integral Part of Iterative Approaches to Design and Organizational Implementation of Large IT Systems

The iterative design process outlined in figure 3 is derived from Simonsen and Hertzum (2008) and emphasizes the evaluation of systems through exposing them to real situated work practices (Suchman, 1987). The starting point of an iteration are the changes that are anticipated and aimed for. The anticipated changes are further specified, for example in 
terms of what effects are expected from using the system. The system (or a part/prototype of it) is then implemented and tried out under conditions as close as possible to real use - a process which is referred to as a pilot study (Rodney Turner, 2005; Glass, 1997). Actual use of the system allows for emergent and opportunity-based changes to occur. The ethnographically based evaluation supports the awareness of such unanticipated changes and informs subsequent iterations, allowing selected emergent changes to be treated as opportunity-based and new anticipated change.

In the following, the process outlined in figure 3 is exemplified through a large-scale case in the Danish healthcare sector. Results from using the ethnographically based evaluation are presented, and the prospects and implications for this role of ethnography are discussed.

\section{The Case}

The case took place in a hospital in Roskilde, Denmark, at a neurological stroke unit treating patients with acute apoplexy. The case is described in detail by Simonsen and Hertzum (2008). An advanced prototype of a large EPR system was designed, implemented, used in a large-scale real-life pilot study, and subjected to an ethnographically based evaluation.

The overall anticipated change that the experiment aimed for was to implement a fully IT functional EPR that included support for the clinical process and replaced all paper-based patient records. The clinicians at the stroke unit specifically requested support in obtaining patient overview and mutual coordination.

The experiment was prepared throughout 5 months. Clinical personnel in cooperation with the vendor (CSC Scandihealth), the hospital's EPR unit, and two researchers (including the author of this article) configured the EPR system supporting the stroke units' patient trajectories. The clinicians used the system 24 hours a day throughout a pilot study lasting one week. The ethnographically based evaluation reported on in this article focused on the clinicians' use of a large shared EPR display during highly collaborative situations.

The anticipated changes were specified in the first part of the experiment during five consecutive full-day PD workshops. Main parts of the system were designed and configured during three consecutive workshops: At one workshop, mock-ups were drawn on flip-over charts. At the following workshop, a preliminary non-interactive PowerPoint prototype was discussed. At a third workshop, a running prototype was demonstrated, discussed, and evaluated.

The vendor undertook the technical development of the EPR system. The system was based on Oracle's Healthcare Transaction Base, comprised of a total of 243 screens, and included real-time integration with the hospital's patient-administrative system, its medication system, and several of its laboratory systems. The system involved stationary and portable PC's and PDAs for bedside measurement of patient parameters (temperature, blood pressure, etc.). Data from the hospital's patients from the previous five years (in total more than 26 million records from 330,000 patients) were migrated to the system prior to the pilot study in order to have access to past information about patients and to obtain a realistic data load.

A 24 hour staffed back-office were established, and Wizard-of-Oz techniques used to simulate a fully integrated system. If the clinicians initiated transactions that included other wards at the hospital (other wards that were not included in the experiment), this would be captured in the back-office, mailed in the conventional fashion, and then when the results 
arrived they would be entered into the system. In this way the clinicians experienced the system as if all transactions were really IT supported (except for maybe a slight time delay).

During the 5 days of the pilot study, we investigated the clinicians' work when using the EPR system. Our observations focused on emergent changes especially regarding the nurses' work during two highly collaborative situations:

- Nursing handover, happening three times a day at the beginning of each nursing shift (7am, 3pm, and $11 \mathrm{pm}$ ) and lasting an hour. In the stroke unit there was no time for the nurses leaving the ward to discuss patients with the nurses on the next shift. During nursing handovers, one nurse was designated as the team leader and provided an overview of the patients at the ward and managed the necessary coordination and exchange of information. This nurse reviewed the patient records immediately prior to the handover and then, during the handover, orally informed the others about patient status and plans for the upcoming shift.

- Team conference, taking place once every weekday, lasting approximately 15 minutes and including all clinicians. The team conference took place within an hour after the nursing handover at the beginning of the day shift. An interdisciplinary assessment of each patient was carried out and plans were revised. The current status of each patient was given orally by a nurse (the team leader from the preceding nursing handover), and an overview of current plans was available by means of a table drawn up on a large whiteboard or by means of, during the pilot study, a shared EPR display projected on the wall.

The nursing handovers and team conferences took place in a designated room where the EPR was displayed by projecting a PC screen onto the wall using a standard projector mounted on the ceiling. We observed 9 nursing handovers and 5 team conferences, all performed using the EPR system. Prior to the pilot study, we got acquainted with these situations by observing 6 nursing handovers and 7 team conferences. In total, the observations of nursing handovers and team conferences comprised 16 hours of clinical work, involving 35 patients and more than 20 clinicians.

Each observation was done by one researcher acting as an observing participant (Blomberg et al., 1993), i.e. sitting in the room where the handover or team conference took place, while being as unobtrusive as possible. All observations were documented by the researchers by writing notes. Selected sessions were audio and video recorded, while the full-motion screen interaction with the EPR system was recorded in parallel.

During the pilot study, the researchers were present at the ward during the day-shift (7am through $4 \mathrm{pm}$ ). This allowed us to ask clarifying questions when the clinicians were not busy as well as to arrange follow-up interviews. We conducted five interviews with three nurses, one physical therapist, and one speech therapist. These interviews elaborated details from our observations and clarified our immediate interpretations. All our interviews have been audio-recorded and later transcribed into extended summaries as part of our field notes. A few days after the pilot study we conducted a group interview with three nurses evaluating their impressions especially with regard to our main observations. Finally, we interviewed the nurse acting as the team leader and presented our results from our ethnographic records, for verification. 
The evaluation and the anonymous involvement of patients were authorized by the hospital. Our observations, interviews, audio-, video-, and screen-recordings were authorized by the stroke unit and approved by the participating clinicians.

\section{Results}

Even though the pilot study lasted only five days, 183 out of in total 482 (almost 4 out of 10) of the clinicians' ideas and suggestions for changes and improvements to the EPR system were recorded during this period where the system was for the first time exposed to real clinical work. This clearly emphasizes the importance of conducting real-life evaluations as part of the overall design and implementation strategy.

Our observations of the traditional paper-based nursing handovers and team conferences (prior to the pilot study) showed a common characteristic regarding the nurse acting as team leader. The nurse team leader would hold the paper record in her hand and read out key status information that she had prepared before the team conference - and the others would listen to her presentation. Thus, the team leader informs the other participants about the patient by reading information from own notes supplemented by the paper-based patient record, which is available to the team leader only. This oral handover of information from the team leader to the other participating clinicians represents a long-standing and common practice within nursing handovers (Strange, 1996). The oral shift report maintains the team leader's role as chair during the handover and constitutes what we can characterize as a gatekeeper (Allen, 1977), controlling access to the information in the patient record. In the pilot study the EPR was displayed on the wall during nursing handovers and team conferences. Such a large shared EPR display reduces the gatekeeper's role to navigating the EPR; its content is available to all participants (see figure 4).

The use of a shared EPR display led to interesting observations identifying changes to the collaboration among the clinicians during nursing handovers and team conferences. We observed an immediate emergent change as the traditional oral way of informing about patient status changed to collectively reading the information on the shared display. This in turn was followed by other unanticipated changes of which we will further elaborate two:

Collective investigation of the patient record at the nursing handover. As a result of the ability to collectively read the patient record on the shared display, we observed that the nurses initiated collective investigations of the patient record: During the use of paper records we observed that patient records were seldom seen by clinicians other than the team leader, except in cases for example where the handwriting was unreadable. During the pilot study patient records (on the shared display) were repeatedly inspected by all nurses present at the handovers, and they collectively participated in interpreting the status and condition of patients. A few collective investigations at the team conference were also identified but this conference does not leave much time for such clarifying investigations (lasting only 15 minutes as compared to the one hour nursing handover).

Sharing nursing observations during the team conference. The nurses experienced how the shared display designed for the team conferences formed the agenda for these conferences. During the pilot study the nurses initiated a change of this screen - influencing the agenda of the team conferences. The change consisted in adding a panel specifying selected nursing observations of relevance to the team conference. This way, the nurses' observations became more salient to the clinicians as they were forming their overview of the status of the patients. 
The nurses themselves were in charge of which of their observations were to be communicated to the other physicians present at the team conferences. The panel required selected and condensed observations to be recorded - and introduced thus more structure than the traditional chronological and narrative nursing report (Strange, 1996).

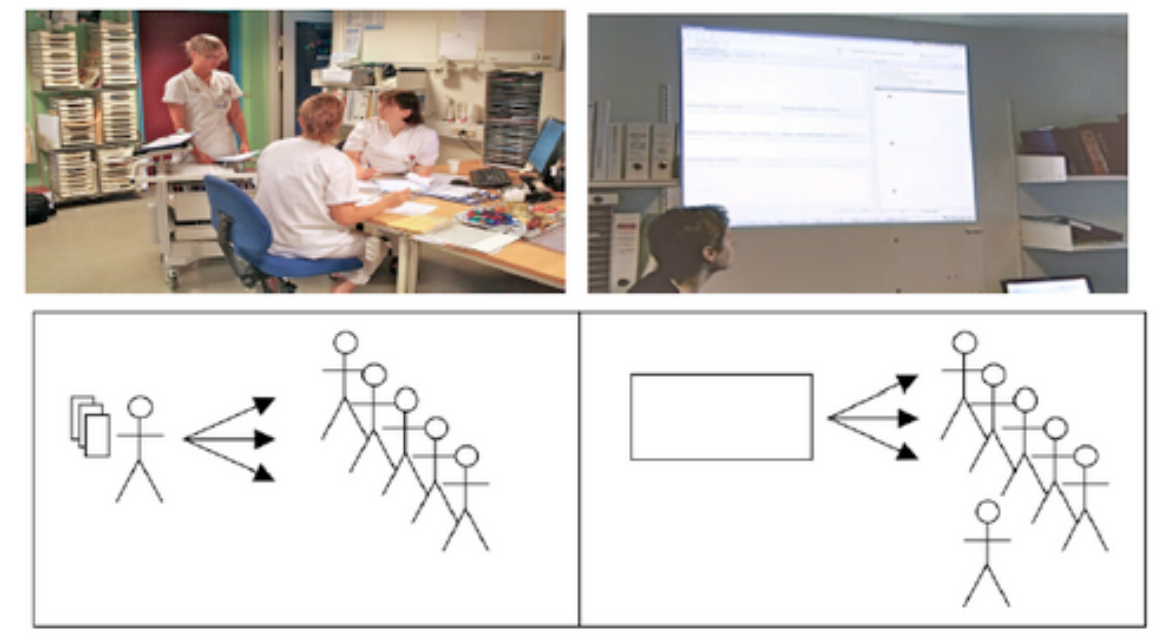

Figure 4: Team Leader Acting as Gatekeeper Controlling Access to the Information in the Paper Record (Left) and Shared Epr Display with Patient Information Visible to all Participants (Right)

The collaboratively available patient records supported the clinicians in getting a more instant and efficient overview, which enabled especially the nurses to engage in collective investigation and, thereby, strengthened their possibilities for gaining thorough insight into patients' conditions.

The collective investigations fostered a mutual learning process where the nurses shared their observations and interpretations and in that way stimulated clarification of open issues and a pursuit of hypotheses about the patient's status and condition. The nurse team leader's role of information gatekeeper faded in favor of a handover characterized by peer-review, second opinions, and the establishment of a professional confidence based on collaboratively developing an understanding of the patients.

The nurses' confidence in their observations was demonstrated at the team conferences. The nurses quickly recognized a possibility for impacting the conference agenda by means of nursing observations visible on the shared display, and they managed to change the design of this display to include their observations. This increased the visibility and prominence of the nurses' work at the team conferences and thereby supported a cross-disciplinary element of clinical work.

\section{Conclusion}

The ethnographic analysis presented in this article investigated how clinical work was affected by making EPR information available on a large, shared display during two situations demanding a high level of coordination: Nursing handovers and team conferences. The analysis 
clarified how new ways of handling their work emerged for the clinicians as they experienced and incorporated the shared EPR display in their collaborative work practice. In summary, we found that the nurses:

- Abandoned oral presentation of patient records in favor of collective reading. This constitutes a substantial departure from a long-standing nursing practice, triggered by the availability of the shared EPR display and quickly encountered and adopted by the nurses.

- Engaged in collective investigation of patient records during change of shift. The shared EPR displays seemed more efficient at providing an overview of patients than oral presentation. This resulted in more nurses taking active part in interpreting the status and condition of patients, hereby stimulating a mutual learning situation and what might be labeled as 'empowering' the nurses (Murnane, 2005).

- Made nursing observations a prominent, shared resource during team conferences. By having a panel with selected nursing observations added to the EPR display, these observations became part of the shared agenda with no further need for nurses to compete and tell about their observations.

These findings provide valuable insights with regard to new possibilities for anticipated change in subsequent iterations of the design and organizational implementation (see figure 3). These insights, among others, include:

- Enabling a different role for the nurse team leader alleviates the preparation time - when there is no traditional oral presentation.

- Organizing team conferences supports and enhances cross-disciplinary information exchange and coordination.

- Designing the user interface to provide specific support for collective investigation of patient records during handovers and team conferences.

- Providing panels and stimulating 'empowerment' occurs for different groups of clinicians with profession specific observations during team conferences (at the stroke unit this includes physicians, nurses, neuropsychologists, occupational therapists, physiotherapists, and speech therapists).

- Enabling a more structured recording making it more accessible and easier for the different groups of clinicians to indicate their observations in panels during team conferences.

The new role for ethnography can be characterized as combining the two traditional roles (see figure 1) and taking a constructive approach as an integral part of the design and implementation of large scale systems. This also gives certain implications.

Pilot studies, like the case described in this article, are very resource demanding and need to balance, on the one hand, evaluating early and quickly to conserve resources, and, on the other hand, evaluating after a longer period of time to allow emergent and opportunity-based changes to develop. In practice, one might expect a tendency towards rather short-term pilot studies. In the case described in this article, the pilot study lasted only 5 days. This requires the ethnographic observations to be well prepared, focused, and critical towards bias:

- The situations to observe must carefully be selected and prioritized, for example in order to allow for observations of 'before-situations' and subsequent comparison with 'aftersituations' where the system is put into use. 
- The time allowed for observations during the use of the system might be very short thus requiring intensive, short-termed observations, also referred to as 'quick-and-dirty' ethnography (Hughes et al., 1995) or 'rapid' ethnography (Millen, 2000).

- The observations must be focused on identifying and analyzing emergent and opportunitybased change with the aim of uncovering which of these should be included as anticipated change in the following iterations or in the final implementation of the system.

- The ethnography must be critical not only in the traditional sense of identifying unintended and undesirable outcomes. A special awareness needs to be ascribed to the limitations, constraints, and biases because of the iterative experiment: This includes for example the learning curve, how well or poorly the users were prepared, the effect of the experiment itself ("being-in-a-study effect"), etc.

The prospect of using ethnography as a means for evaluating emergent changes yields methodological implications for how to develop and evaluate IT systems such as EPR systems. Used consistently, through several iterative cycles, such ethnographically based evaluations might identify and select emergent changes and turn them into new planned ahead anticipated changes in the subsequent implementation of the system. In this way, ethnography can be expanded with regards to its traditional role from a descriptive role (describing existing work practices or the situation after a complete implementation) to an active part of the design and organizational implementation process and focusing on appropriating new IT to the work practices of the users. This constructive role of ethnography represents a change from a descriptive observer to what resembles the participatory designer. With the expansion of this role, ethnography can help incorporate the evolving capabilities, emerging practices, and unanticipated outcomes, and thus support the adaption of both the technology and the organization appropriately and effectively.

\section{References}

Allen, T.J. (1977) Managing the Flow of Technology: Technology Transfer and the Dissemination of Technological Information within the R\&D Organization. MIT Press, Cambridge, MA.

Appelt, W. (1999) WWW Based Collaboration with the BSCW System. Proceedings of SOFSEM'99, Nov. 26. - Dec. 4., Milovy, Czech Republic, Springer Lecture Notes in Computer Science $1725,66-78$.

Balka, E., Wagner, I. \& Jensen, C.B. (2005) Reconfiguring critical computing in an era of configurability. Proceedings of the 4th decennial conference on Critical computing: between sense and sensibility, 79-88.

Bansler, J. \& Havn, E. (1994) Information Systems Development with Generic Systems. Proceedings of the Second European Conference on Information Systems, Nijenrode University Press, 707-715.

Bentley, R.T., Horstmann, T. \& Trevor, J. (1997) The World Wide Web as enabling technology for CSCW: The case of BSCW. CSCW: The Journal of Computer-Supported Cooperative Work, 6, 111-134.

Berg, M., Aarts, J. \& Lei, J.v.d. (2003) ICT in Health Care: Sociotechnical Approaches. Methods of Information in Medicine, 42, 297-301.

Berg, M. (1999) Patient care information systems and health care work: a sociotechnical approach. International Journal of Medical Informatics, 55, 87-101. 
Blomberg, J. et al. (1993) Ethnographic Field Methods and Their Relation to Design. In Participatory Design: Principles and Practices, (Eds, Schuler, D. \& Namioka, A.) Lawrence Erlbaum Associates, Publishers, London, UK, pp. 123-155.

Bødker, K., Kensing, F. \& Simonsen, J. (2004) Participatory IT Design. Designing for Business and Workplace Realities. MIT press, Cambridge, Massachusetts.

Budde, R. et al. (1992) Prototyping: An Approach to Evolutionary System Development. SpringerVerlag, Berlin.

Carroll, J.M., Kellog, W.A. \& Rosson, M.B. (1991) The Task-Artifact Cycle. In Designing Interaction: Psychology at the Human-Computer Interface, (Ed, Carroll, J.M.) Cambridge University Press, Cambridge, pp. 74-102.

Christensen, M. et al. (1998) The M.A.D. experience: Multiperspective application development in evolutionary prototyping. Proceedings of ECOOP'98, Brussels, Belgium, July 20-24, 1998, 1445/1998, Springer Berlin (Lecture Notes in Computer Science), 13-40.

Clement, A. \& Besselaar, P.V.d. (1993) A Retrospective Look at PD Projects. Communications of the $A C M$, 36, 29-37.

Davis, A.M. (1990) Software Requirements: Analysis and Specification. Prentice-Hall, Englewood Cliffs, New Jersey.

Ehn, P. (1988) Work-Oriented Design of Computer Artifacts. Arbetslivcentrum, Stockholm, Sweden.

Floyd, C. (1984) A Systematic Look at Prototyping. In Approaches to Prototyping, (Eds, Budde, R., Kuhlenkamp, K., Mathiassen, L. \& Zullighoven, H.) Springer Verlag, Berlin, pp. 1-18.

Glass, R.L. (1997) Pilot studies: What, why and how. The Journal of Systems \& Software, 36, 85-97.

Greenbaum, J. \& Kyng, M. (Eds.) (1991) Design at Work: Cooperative Design of Computer Systems Lawrence Erlbaum Associates, Chichester, UK.

Hartswood, M.J. et al. (2003a) Working IT out in medical practice: IT systems design and development as co-realisation. Methods of Information in Medicine, 42, 392-397.

Hartswood, M. et al. (2003b) Making a Case in Medical Work: Implications for the Electronic Medical Record. Computer Supported Cooperative Work, 12, 241-266.

Hughes, J.A., Randall, D. \& Shapiro, D. (1993) From Ethnographic Record to System Design: Some Experiences From the Field. Computer Supported Cooperative Work (CSCW): An International Journal, 1, 123-141.

Hughes, J. et al. (1995) Presenting Ethnography in the Requirements Process. Proceedings of the Second IEEE International Symposium on Requirements Engineering (RE '95), IEEE Computer Society, 27-34.

Jirotka, M. et al. (2005) Collaboration and Trust in Healthcare Innovation: The eDiaMoND Case Study. Computer Supported Cooperative Work, 14, 369-398.

Kensing, F. (2000) Participatory Design in a Commercial Context - a conceptual framework. PDC 2000 Proceedings of the Participatory Design Conference, New York, NY, USA, 28 November - 1 December 2000, 116-126.

Kensing, F., Simonsen, J. \& Bødker, K. (1998) Participatory Design at a Radio Station. Computer Supported Cooperative Work, 7, 243-271.

Luff, P., Hindmarsh, J. \& Heath, C.C. (2000) Workplace studies: recovering work practice and informing system design. Cambrigde University Press, Cambridge.

Millen, D.R. (2000) Rapid ethnography: time deepening strategies for HCI field research. DIS '00: Proceedings of the 3rd conference on Designing interactive systems: processes, practices, methods, and techniques, ACM Press, 280-286.

Murnane, R. (2005) Empowering nurses_-Improving care: Nurses' response to the new Health Services Reform Programme in Ireland. International Journal of Medical Informatics, 74, 861-868.

Oostveen, A.-M. \& Besselaar, P.v.d. (2004) From small scale to large scale user participation: a case study of participatory design in e-government systems. Proceedings of the eighth Participatory Design Conference 2004, Artful Integration: Interweaving Media, Materials and Practices (PDC 2004), I, ACM Press, 173-182. 
Orlikowski, W. \& Hofman, D. (1997) An improvisational model for change management: The case of Groupware technologies. Sloan Management Review, 38, 11-22.

Orlikowski, W.J. (1996) Evolving with Notes: Organizational Change around Groupware Technology. In Groupware and Teamwork. Invisible Aid or Technical Hindrance?, (Ed, Ciborra, C.U.) John Wiley \& Sons, Chichester, pp. 23-59.

Pirnejad, H. et al. (2008) Impact of a computerized physician order entry system on nurse-physician collaboration in the medication process. International Journal of Medical Informatics, 77, 735-733.

Plowman, L., Rogers, Y. \& Ramage, M. (1995) What Are Workplace Studies For? Proceedings of the Fourth European Conference on Computer-Supported Cooperative Work, September 10-14, Stockholm, Sweeden, Kluwer Academic Publishers, Dordrecht, 309-324.

Rodney Turner, J. (2005) The role of pilot studies in reducing risk on projects and programmes. International Journal of Project Management, 23, 1-6.

Schuler, D. \& Namioka, A. (Eds.) (1993) Participatory Design: Principles and Practices Lawrence Erlbaum Associates, London, UK.

Sismondo, S. (2003) An Introduction to Science and Technology Studies. Blackwell Publishing,

Simonsen, J. \& Hertzum, M. (2008) Participatory Design and the Challenges of Large-Scale Systems: Extending the Iterative PD Approach. Proceedings of the 10th anniversary conference on Participatory Design: Experiences and Challenges, September 30 - October 4, 2008, Bloomington, Indiana, USA, ACM Press, 1-10.

Simonsen, J. \& Kensing, F. (1997) Using Ethnography in Contextual Design. Communications of the $A C M, \mathbf{4 0}, 82-88$.

Simonsen, J. \& Kensing, F. (1998) Make Room for Ethnography in Design! The Journal of Computer Documentation, 22, 20-30.

Sommerville, I. et al. (1992) Sociologists can be surprisingly useful in interactive systems design. Proceedings of HCI'92, York University, September 1992, People and Computers, VII, Cambridge University Press, 341-353.

Stoop, A.P. \& Berg, M. (2003) Integrating Quantitative and Qualitative Methods in Patient Care Information System Evaluation: Guidance for the Organizational Decision Maker. Methods of Information in Medicine, 42, 458-462.

Strange, F. (1996) Handover: an ethnographic study of ritual in nursing practice. Intensive and Critical Care Nursing, 12, 106-112.

Suchman, L.A. (1987) Plans and Situated Actions: The Problem of Human-Machine Communication. Cambridge University Press, Cambridge, New York.

\section{About the Author}

Jesper Simonsen

My area of expertise is Participatory Design (PD) focusing on offering theories and methods for IT design in an organizational context. This research area also includes Computer Supported Cooperative Work (CSCW), Knowledge Management (KM), Human Computer Interaction (HCI), and Computer Mediated Communication (CMC). I have since 1991 conducted research in collaboration with industry on IT design focusing on how IT designers can cooperate with users and their management especially relating to the clarification of goals, formulation of needs, and design and evaluation of coherent visions for change. 


\section{DESIGN PRINCIPLES \& PRACTICES}

\section{An International Journal}

\section{EDITORS}

Bill Cope, University of Illinois, Urbana-Champaign, USA.

Mary Kalantzis, University of Illinois, Urbana-Champaign, USA

\section{EDITORIAL ADVISORY BOARD}

Genevieve Bell, Intel Corporation, Santa Clara, USA.

Michael Biggs, University of Hertfordshire, Hertfordshire, UK.

Thomas Binder, Royal Danish Academy of Fine Arts, Copenhagen, Denmark.

Jeanette Blomberg, IBM Almaden Research Center, San Jose, USA.

Eva Brandt, Danmark Designskole, Copenhagen, Denmark.

Peter Burrows, RMIT University, Melbourne, Australia.

Monika Büscher, Lancaster University, Lancaster, UK.

Patrick Dillon, Exeter University, Exeter, UK.

Kees Dorst, TUe, The Netherlands; UTS, Australia.

Ken Friedman, Swinburne University of Technology, Melbourne, Australia; Denmark's Design School, Copenhagen, Denmark.

Michael Gibson, University of North Texas, Denton, USA.

Judith Gregory, IIT Institute of Design, Chicago, USA; University of Oslo, Oslo, Norway.

Clive Holtham, City of London University, London, UK.

Hiroshi Ishii, MIT Media Lab, Cambridge, USA.

Gianni Jacucci, University of Trento, Trento, Italy.

Klaus Krippendorff, University of Pennsylvania, Philadelphia, USA.

Terence Love, Curtin University, Perth, Australia.

Bill Lucas, MAYA Fellow, MAYA Design, Inc., Pittsburgh, USA.

Ezio Manzini, Politecnico of Milano, Milan, Italy.

Julian Orr, Work Practice \& Technology Associates, Pescadero, USA.

Mahendra Patel, Leaf Design, Mumbai, India.

Toni Robertson, University of Technology Sydney, Sydney, Australia.

Terry Rosenberg, Goldsmiths, University of London, London, UK.

Keith Russell, University of Newcastle, Callaghan, Australia.

Liz Sanders, Make Tools, USA.

Maria Cecilia Loschiavo dos Santos, University of São Paulo, São Paulo, Brazil.

Lucy Suchman, Lancaster University, Lancaster, UK.

Ina Wagner, Technical University of Vienna, Vienna, Austria.

Please visit the Journal website at http://www.Design-Journal.com for further information about the Journal or to subscribe. 


\section{THE UNIVERSITY PRESS JOURNALS}

\section{The International $f_{\text {tbe }}$ ARTS IN SOCIETY}

Creates a space for dialogue on innovative theories and practices in the arts, and their inter-relationships with society.

ISSN : 1833-1866

http://www.Arts-Journal.com

\section{DESIGN PRINCIPLES \& PRACTICES}

Examines the meaning and purpose of 'design' while also speaking in grounded ways about the task of design and the use of designed artefacts and processes.

ISSN: 1833-1874

http://www.Design-Journal.com

\section{THE GLOBAL STUDIES JOURNAL}

Maps and interprets new trends and patterns in globalisation.

ISSN 1835-4432

http://www.GlobalStudiesJournal.com

\section{The Irementional Of LEARNING}

Sets out to foster inquiry, invite dialogue and build a body of knowledge on the nature and future of learning.

ISSN: $1447-9540$

http://www.Learning-Journal.com

\section{The Intremational $f_{\text {bis }}$ INCLUSIVE MUSEUM}

Addresses the key question: How can the institution of the museum become more inclusive?

ISSN 1835-2014

http://www.Museum-Journal.com

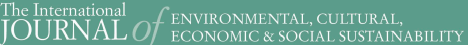

Draws from the various fields and perspectives through which we can address fundamental questions of sustainability.

ISSN: 1832-2077

http://www.Sustainability-Journal.com

\section{UBIQUITOUS LEARNING}

Investigates the affordances for learning in the digital media, in school and throughout everyday life.

$$
\text { ISSN 1835-2030 }
$$

http://www.ULJournal.com

\section{The International $f_{f}$ BOOK}

Explores the past, present and future of books, publishing, libraries, information, literacy and learning in the information society. ISSN: 1447-9567 http://www.Book-Journal.com

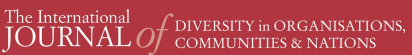

Provides a forum for discussion and builds a body of knowledge on the forms and dynamics of difference and diversity. ISSN: 1447-9583

http://www.Diversity-Journal.com

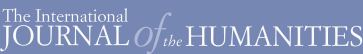

Discusses the role of the humanities in contemplating the future and the human, in an era otherwise dominated by scientific, technical and economic rationalisms.

ISSN: 1447-9559

http://www.Humanities-Journal.com

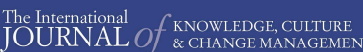

Creates a space for discussion of the nature and future of organisations, in all their forms and manifestations.

ISSN: 1447-9575

http://www.Management-Journal.com

\section{Tho Intermational $O$ INTIRDDISCIPLINARY SOCIAL SCIINNCES}

Discusses disciplinary and interdisciplinary approaches to knowledge creation within and across the various social sciences and between the social, natural and applied sciences.

ISSN: 1833-1882

http://www.Socialsciences-Journal.com

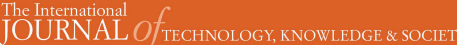

Focuses on a range of critically important themes in the various fields that address the complex and subtle relationships between technology, knowledge and society.

ISSN: 1832-3669

http://www.Technology-Journal.com

\section{JOURNAL $O f_{\text {tbe }}$ World Universities Forum}

Explores the meaning and purpose of the academy in times of striking social transformation. ISSN $1835-2030$ http://www.Universities-Journal.com

\section{FOR SUBSCRIPTION INFORMATION, PLEASE CONTACT}

subscriptions@commonground.com.au 